\title{
Stefan Zweig: um homem de ontem? Entrevista com Klemens Renoldner
}

\author{
[Stefan Zweig: A Man of Yesterday? An Interview with Klemens Renoldner] \\ http://dx.doi.org/10.1590/1982-883718267236257
}

por Ruth Bohunovsky ${ }^{1}$

\begin{abstract}
The curator of the exhibition We need an entirely different courage! Stefan Zweig farewell to Europe, Klemens Renoldner, discusses in this interview the relation between texts and contexts with respect to the work of the Austrian writer Stefan Zweig (1881-1942). He brings out different contexts of reception and different interpretative approaches, that can put traditional stereotypes about the life and work of the author into new perspectives. The conversation also deals with the cooperation between the Stefan Zweig Centre in Salzburg and the Casa Stefan Zweig in Petrópolis (Rio de Janeiro) and mentions joint projects that have already been realized, as well as future projects.
\end{abstract}

Keywords: Stefan Zweig; exile; Brazil

Zusammenfassung: Der Kurator der Ausstellung Wir brauchen einen ganz anderen Mut! Stefan Zweig - Abschied von Europa, Klemens Renoldner, spricht im Interview über Text-KontextBeziehungen in Hinblick auf das Werk des österreichischen Schriftstellers Stefan Zweig (18811942). Dabei kommen u.a. unterschiedliche Rezeptionskontexte und Interpretationsansätze ans Licht, die dazu beitragen, traditionelle Klischees rund um das Leben und das Werk des Autors zu relativieren. Außerdem wird auf die Zusammenarbeit des Stefan Zweig Centres in Salzburg und der Casa Stefan Zweig in Petrópolis (Rio de Janeiro) hingewiesen und abgeschlossene, sowie zukünftige Projekte vorgestellt.

Stichwörter: Stefan Zweig; Exil; Brasilien

Resumo: Klemens Renoldner, curador da exposição Precisamos de uma coragem bem diferente! - Stefan Zweig - despedida da Europa, aborda, em entrevista, as relações entre entre textos e contextos no âmbito da obra do escritor austríaco Stefan Zweig (1881-1942). Com isso, traz à tona diferentes contextos de recepção e vertentes interpretativas da obra zweigiana, contribuindo assim à relativização de tradicionais clichês em torno da vida e da obra do autor. Além disso, a conversa trata da cooperação entre o Stefan Zweig Centre, em Salzburgo, e a Casa Stefan Zweig, em Petrópolis (Rio de Janeiro), e apresenta projetos realizados e futuros.

Palavras-chave: Stefan Zweig; exílio; Brasil

\footnotetext{
${ }^{1}$ Universidade Federal do Paraná, Setor de Ciências Humanas (SCH), Rua General Carneiro, 460, Edifício D. Pedro I, 80.060-150, Curitiba, PR, Brasil. Email: ruth.bohunovsky@uol.com.br
} 


\section{Introdução}

Nos anos de 1920 e 1930, ele era um dos escritores mais traduzidos no mundo; na França, continua sendo um dos mais apreciados autores de língua alemã; na Alemanha e na Áustria, no campo dos estudos de germanística, sua fama é a de um "escritor de sexta categoria". Mas num recente documentário veiculado por uma rede de televisão austríaca, ele foi considerado (ao lado de Leopoldina de Habsburgo) como um dos dois "mais famosos austríacos exilados no Brasil", e um livro sobre sua vida sexual vem despertando a comoção do público leitor de língua alemã. No mundo anglo-saxão, seu nome havia caído em esquecimento até o lançamento do filme Grande Hotel Budapeste, que o fez reaparecer nas mídias e nas listas de publicações. No Brasil, apenas parte da sua obra foi traduzida, mas em 2014 foi relançada, numa nova tradução, sua autobiografia e publicada sua última agenda telefônica; desde 2013, a editora Zahar vem publicando novas edições de obras selecionadas. E desde 2014, uma grande exposição sobre sua vida e sua obra no exílio vem sendo exibida em diversas cidades europeias e assim esperamos - também percorrerá o Brasil. Estamos falando de Stefan Zweig ${ }^{2}$, cuja vida e cuja obra têm igualmente despertado interesse e motivado a elevada fama do escritor. Na entrevista a seguir, Klemens Renoldner, curador da exposição e diretor do Stefan Zweig Centre em Salzburgo conta sobre o autor, a exposição, a recepção e o lugar de Zweig no contexto internacional, assim como sobre projetos em comum entre o Zweig Centre e a Casa Stefan Zweig - um museu e memorial dedicado a Zweig e a outros escritores exilados, localizado na última morada de Zweig, em Petrópolis, no Rio de Janeiro.

A exposição "Precisamos de uma coragem bem diferente! Stefan Zweig despedida da Europa" foi inaugurada no Museu do Teatro, em Viena, em 2014. Após Viena (de abril de 2014 a janeiro de 2015). A mostra foi exibida ainda na Casa de Literatura em Munique e no Instituto Cultural de Tirol do Sul, em Bozen. A partir de 24

2 Desde 2013, a editora Zahar vem publicando novas edições de obras selecionadas de Stefan Zweig, sempre acompanhadas por comentários de Alberto Dines: O mundo insone e outros ensaios (2013, organização de Alberto Dines, tradução de Kristina Michahelles); Maria Antonieta (2013, tradução de Irene Aron); Autobiografia: o mundo de ontem (2014, tradução de Kristina Michahelles); Três novelas femininas - Medo, Carta de uma desconhecida, 24 horas na vida de uma mulher (2014; tradução de Adriana Lisboa, Raquel Abi-Sâmara);Joseph Fouché - retrato de um homem político (2015, tradução de Kristina Michahelles) Novelas insólitas - Segredo ardente, Confusão de sentimentos, A coleção invisível, Júpiter, Foi ele?, Xadrez - uma novela (2015, tradução de Maria Aparecida Barbosa, Kristina Michahelles e Murilo Jardelino). Para 2016 está previsa a publicação de Cura pelo espírito, numa tradução de Kristina Michahelles. 
de novembro de 2015, será possível visitá-la na Biblioteca Nacional Alemã de Frankfurt. $\mathrm{O}$ foco temático da mostra é a vida e a obra do escritor a partir da perspectiva do exílio. A última parada do percurso de Zweig no exílio foi o Brasil, e foi aqui, em Petrópolis, que Zweig se suicidou com sua segunda esposa Lotte, em fevereiro de 1942. Ele estava então com 60 anos. Deixou para trás uma bem-sucedida carreira internacional como escritor, uma vida intensamente interligada a um grande número de pensadores e artistas europeus, assim como o fim do seu "mundo de ontem", destruído durante a Primeira Guerra Mundial; a incineração pública das suas obras pelos nazistas e a destruição do seu ambiente intelectual, que se iniciara mesmo antes da "anexação" da Áustria pelo Reich alemão; e o início da Segunda Guerra Mundial.

Stefan Zweig exilou-se em fevereiro de 1934 (ficou seis anos e meio na GrãBretanha; depois residiu em diversos lugares do Brasil; e entre janeiro de 1941 e fevereiro de 1942, morou em Petrópolis, perto do Rio de Janeiro). Já em 1933, numa carta para o pintor belga Frans Masereel, Zweig expôs sua "grande aversão a tornar-se um emigrante", pois tinha plena consciência de que "toda emigração" era "perigosa", ao transformar "aqueles que ficaram em reféns" (RENOLDNER 2014: 7). Mas Zweig também sabia que justamente as obras escritas no exterior poderiam ter um papel de destaque nas suas respectivas literaturas nacionais (ibid.). Sem dúvida, isso vale para as obras que o próprio Zweig escreveu no exílio, especialmente para Xadrez e suas memórias $O$ mundo de ontem - ambas ocupam um lugar especial no âmbito da obra zweigiana e na referida exposição. Entre as obras relevantes que redigiu no período de exílio, também estão: Erasmo de Rotterdam, grandeza e decadência de uma ideia [Triumph und Tragik des Erasmus von Rotterdam] (1936); Uma consciência contra a violência: Castélio contra Calvino [Castellio gegen Calvin, oder: Ein Gewissen gegen die Gewalt] (1936); os trabalhos biográficos Maria Stuart (1935), Fernão de Magalhães [Magellan] (1938) e Américo Vespúcio (1942); o romance Coração Inquieto [Ungeduld des Herzens], assim como Brasil - um país do futuro (1941).

A referida exposição não se limita a pôr a obra de exílio de Zweig no centro das atenções: também sua organização espacial é marcada pelo assunto da expatriação. Toda a mostra está disposta num ambiente que procura recriar o Hotel Metrópole de Viena, que, após tempos de glória, foi transformado pela Gestapo num centro de detenção e tortura - e é um dos locais onde é ambientado o livro Xadrez. Na exposição, o hotel simboliza a ruptura e a violência do exílio. 
Num gesto de despedida, durante sua última visita a Viena, em 1937, Zweig entregou toda sua enorme coleção de manuscritos ao Acervo de Teatro da Biblioteca Nacional da Áustria. Até hoje pouco conhecida, a coleção contém manuscritos de autores como Franz Kafka, Thomas Mann, Hermann Hesse e Else Lasker-Schüler). Algumas dessas preciosidades podem ser vistas na presente exposição.

Klemens Renoldner já era especialista em Zweig bem antes de se tornar o diretor do Stefan Zweig Centre de Salzburgo, em 2008. Em 1992, já havia idealizado uma grande exposição sobre Stefan Zweig em Salzburgo. Essa primeira mostra foi exibida, em versão reduzida, em diversos países, inclusive no Brasil (em 1996, em São Paulo; e mais tarde, em Salvador, na Bahia). Além disso, Klemens Renoldner atuou como dramaturgo no Teatro Municipal de Viena e no Festival de Teatro de Viena, bem como em teatros na Suíça e na Alemanha. Atualmente, dedica-se ao trabalho acadêmico e atua como docente nas Universidades de Salzburgo, Bern, Freiburg, Innsbruck e Verona. É autor de uma longa lista de artigos, sobretudo sobre Stefan Zweig. Recentemente, publicou uma edição comentada de Xadrez (na editora Reclam), e em 2015 organizou o livro A Inglaterra de Stefan Zweig, junto com Rüdiger Görner (na editora Könighausen \& Neumann). É também autor de títulos de prosa, como A impaciência de Lily (2014), romance sobre o suicídio de uma estudante de 24 anos.

Bohunovsky: A perspectiva da exposição Precisamos de uma coragem bem diferente! Stefan Zweig: Despedida da Europa é a do exílio, tanto no sentido temático (no centro da mostra estão as obras de exílio $\mathrm{O}$ mundo de ontem $e$ Xadrez) quanto no que diz. respeito à organização espacial da exposição, que circunda o hotel de luxo Metrópole (de onde o mundo refinado do Fin de Siècle teve de se retirar para ceder o espaço ao terror nazista). Minhas perguntas: qual foi o motivo para definir a perspectiva do exílio como determinante para a mostra? Essa perspectiva é interessante também para o público de língua alemã? Essa visão tem algo a ver com a atual situação política da Europa (já que o título da exposição poderia ser entendido como uma alusão à crise migratória na Europa de hoje ou como um convite à atuação nesse contexto)?

RENOLDNER: Em primeiro lugar, eu vejo a vida e a obra de Stefan Zweig inseridas nas coordenadas da história política da Áustria e da Europa. E, obviamente, do mundo. Apenas num segundo momento é que vejo a relação com a fascinante época 
literária e cultural em que Zweig viveu. A Monarquia dos Habsburgos, a Primeira Guerra Mundial, a democracia e a Primeira República da Áustria, depois as ditaduras alemã e austríaca e a Segunda Guerra Mundial, todas essas mudanças, transições e transformações marcaram Zweig e desafiaram-no intelectualmente, no sentido de desenvolver e modificar seu modelo específico de autoria. Podemos ver também os dois polos entre os quais está inserida sua obra: a vida intelectual de Viena e da Áustria, por um lado, e o continente europeu, com sua cultura e suas tradições, por outro lado. Para Zweig, não eram apenas os modismos literários e intelectuais da Áustria e da Alemanha que tinham relevância, mas também aqueles que chegavam da Itália, da França, da Inglaterra, da Rússia, etc.

Zweig vivenciou duas Guerras Mundiais, a ditadura de Hitler a partir de 1933 e suas consequências para a política austríaca. A perseguição e o assassinato de judeus fizerem do escritor um emigrante. Ouve-se frequentemente, e não sem razão, que Zweig era apolítico, além de ser uma pessoa bastante reservada e medrosa, que não queria se defender nem "lutar" publicamente e que se tornou, contra a sua vontade, uma vítima da História.

Ao mesmo tempo, é preciso dizer que ele observava atentamente as transformações e os desdobramentos políticos na Europa, que estava sempre muito bem informado (o que podemos verificar, por exemplo, na correspondência entre ele e Romain Rolland) e que expressava opiniões bem claras. De modo geral, seu posicionamento é visto como ambivalente. Durante os anos de exílio, tal ambivalência ficou bastante explícita, por seu distanciamento dos acontecimentos políticos, mesmo sentindo-se diretamente afetado por eles, e por seu comedido silêncio em relação aos eventos históricos e políticos.

Desta vez, não pretendíamos montar uma exposição biográfica. Não nos interessamos pela história privada, íntima, da vida de Zweig, mas sim pela sua busca por um posicionamento intelectual adequado durante os anos do seu exílio. Em 1992, por ocasião do cinquentenário de morte de Zweig, Peter Karlhuber e eu organizamos [em Salzburgo] uma grande exposição sobre Zweig, com a intenção de abranger toda a sua obra e a sua vida. Para nossa surpresa, a mostra teve grande sucesso, também em nível internacional, e foi levada, em versão reduzida, ao Brasil, inclusive. Obviamente, não queríamos nos repetir na atual exposição. Além disso, pretendíamos criar uma exposição sobre Zweig com enfoque na política e na literatura. Tivemos que escolher os 
títulos sobre os quais queríamos contar algo.

Decidimo-nos por Xadrez e $O$ mundo de ontem. Trata-se dos dois últimos textos que Zweig conseguiu terminar e nos quais se referiu à destruição do seu Lebenswelt na Áustria. O velho e o novo mundo, a catástrofe e a utopia, a Europa e o exílio, o velho mundo burguês e o novo começo num ambiente incerto - esses são os polos temáticos que marcam esses livros. Em outras de suas obras escritas após 1933 (refiro-me àquelas sobre Erasmo de Roterdã e sobre João Calvino e seu oponente Castélio), Zweig tomou o caminhou das analogias históricas para falar sobre os temas ditadura e tolerância. Para tal, voltou à história da Reforma. Tal "desvio" para a história foi algo bem comum entre escritores exilados - e algo bastante compreensível. Esses livros foram também considerados na exposição. E, evidentemente, Brasil - um país do futuro também foi integrado. De um modo geral, o Brasil ocupa um papel importante na mostra.

Ao escolhermos Xadrez e $O$ mundo de ontem, levamos também em consideração o fato de serem os livros mais conhecidos de Zweig e os mais adequados para evidenciar paralelo com os tempos atuais: Zweig fugia de um país para outro para escapar de Hitler e da guerra. Milhares de pessoas compartilham atualmente esse destino. Em Viena, colocamos na entrada da exposição um texto de Zweig sobre o destino dos fugitivos judeus. Sua descrição concreta e real soa muito atual. O tema pode ser abordado também nas escolas, como ponto de partida para discussões sobre a política contemporânea. Tal relação sempre foi de grande importância para nós. Nosso objetivo não é mostrar Zweig como um homem da História, como um "homem de ontem", mas como alguém cuja história de vida nos remete diretamente ao presente. No meu entender, é desse modo que devemos olhar para a literatura: entender que ela tem algo a ver conosco, que nos coloca perguntas.

A ideia maravilhosa para a exposição veio de Peter Karlhuber: de um lado, mostrar o universo feliz, luxuoso, burguês em que estava inserido o sucesso de Zweig e no qual ele vivera. Damos informações sobre sua posição no mundo literário, sua fama internacional, sua fascinante rede de amigos artistas e intelectuais. Mostramos traduções de seus livros, fotos da época das viagens felizes, despreocupadas. De outro lado, exibimos a destruição desse intacto mundo burguês e a transformação de um hotel de luxo de Viena em um lugar onde ocorre a maior barbaridade possível. O antigo GrandHotel Métropole, em Viena, é um dos cenários centrais do enredo de Xadrez e representa justamente esses dois polos da nossa exposição, ilustrando a transformação 
do luxo burguês em terror nazista. Essa tensão é o centro oculto da nossa mostra.

BOHUNOVSKY: Você mencionou que o Brasil ocupa um importante papel na exposição atual. Poderia falar um pouco mais sobre isso?

RENOLDNER: Em 1936, Stefan Zweig atravessou pela primeira vez o Atlântico, para viajar ao Brasil. A foto que o mostra no convés do navio Alcântara é o símbolo da exposição. Outra vitrine exibe documentos da pesquisa que Zweig empreendeu para seu livro sobre o Brasil - entre os quais, um mapa geográfico (concedido pela Casa Stefan Zweig de Petrópolis), no qual estão registradas todas as viagens que Zweig fez no país, a fim de coletar informações para seu livro. Além disso, expomos diversas fotos tiradas durante sua permanência no Brasil, tais como a que o retrata ao lado de Getúlio Vargas.

A Casa Stefan Zweig e a Biblioteca Nacional do Rio concederam-nos manuscritos, fotos e documentos que estão expostos em reproduções. Em Munique, pudemos também mostrar o documentário Zweig: a morte em cena ${ }^{3}$, do diretor brasileiro Sylvio Back - um filme maravilhoso, com depoimentos de amigos e contemporâneos de Zweig. Vale mencionar, ainda, que Xadrez foi escrito no Brasil e que a exposição traz, por exemplo, a primeira edição dessa obra e também de $O$ mundo de ontem. Ainda, reunimos fotos do editor brasileiro Abrahão Koogan e sua esposa, amigos e conhecidos de Zweig no Brasil; a carta de despedida do autor, escrita em Petrópolis, em 22 de fevereiro de 1942; a sua certidão de óbito, emitida por um médico brasileiro; entre outros documentos. A peça mais importante é certamente a referida foto no navio, de 1936, que mostra Zweig, então com 55 anos, na sua viagem do velho ao novo mundo e que podemos entender como o lema da exposição.

BOHUNOVSKY: Assim como os milhões de fugitivos que, atualmente, estão chegando à Europa, Zweig deixou para trás uma vida inteira, na tentativa de construir uma nova no Brasil, e fracassou, apesar de sempre ter ocupado posição privilegiada em terras brasileiras e de nunca ter sido aqui apenas um exilado entre muitos. Diferentemente da maioria dos seus colegas escritores que também fugiam dos nazistas, Zweig estabeleceu-se no Brasil, e isso não aconteceu por acaso (como, por exemplo, no caso

\footnotetext{
${ }^{3} \mathrm{O}$ filme pode ser visto pelo site YouTube: https://www.youtube.com/watch?v=NmACHd8yHjs.
} 
de Ulrich Becher, cujo objetivo sempre fora chegar aos Estados Unidos e que via no Brasil apenas uma morada provisória). Zweig havia lido as obras de Hermann Graf KEYSERLING (em especial, as Meditações sul-americanas) e conversado pessoalmente com esse polêmico filósofo, e, inspirado por ele, via no Brasil um polo oposto da Europa, e lhe parecia bastante interessante. Já em 1928, anos antes da sua primeira visita ao Brasil, referia-se aos "novos impulsos" para o mundo que vinham de países como o Brasil e a Argentina. Keyserling - e, em consequência, também Stefan Zweig - defendia a ideia de que países fora da Europa poderiam contribuir para uma "regeneração" do mundo. O livro Brasil - um país do futuro é uma manifestação do sonho (utópico?) de Zweig de um entendimento entre os povos e do seu engajamento como defensor do Brasil no contexto europeu. Ou seja, Zweig veio ao Brasil com uma ideia preconcebida sobre o país. Essa ideia teria sido mantida? Ou, numa formulação mais provocativa: seu suicídio teria sido unicamente uma reação à perda do seu "mundo de ontem" ou talvez também ao reconhecimento de que o "mundo de amanhã”, isto é, o Brasil, talvez não correspondesse integralmente às ideias utópicas de Keyserling?

RENOLDNER: Não me parece tão claro que Zweig tenha planejado construir uma nova vida no Brasil. Penso muito mais que o Brasil teria sido uma opção entre muitas. Ele nunca chegou ao ponto de querer tornar o país numa nova pátria. Acho que ainda não havia chegado tão longe. Talvez isso tivesse acontecido num momento posterior, num lugar especial. Na minha compreensão, o Brasil não foi a parada final para Zweig, mas uma escala no caminho para outro lugar, o lugar certo, que poderia se tornar o “seu” lugar. Mas tal lugar já não existiria para Zweig, pois imagino que seria um lugar na Europa, no mundo perdido "de ontem". Em 1942, no meio da guerra, isso parecia absolutamente impossível.

Na primavera de 1942 - quando a Inglaterra temia, com razão, a ocupação pelas tropas nazistas, que já se encontravam na França - Zweig decidiu deixar o continente europeu. Num primeiro momento, seu objetivo era chegar aos Estados Unidos. Em diversas cartas, Zweig se mostrou bastante decepcionado por ter recebido apenas um visto de trânsito pela embaixada americana em Londres. Suas boas relações com o Brasil ajudaram-no a receber um visto permanente para o país sul-americano. Já acalentava a ideia de escrever um livro sobre o Brasil (alguns capítulos já estavam redigidos). Assim, viajou ao país, onde ficou cinco meses. Visitou vários lugares, fez 
pesquisas e continuou a escrita do livro. (Na exposição, mostramos bem os registros dessa viagem.) Passou os meses entre janeiro e setembro de 1941 novamente nos Estados Unidos, onde morou em diversas cidades, em Nova York, New Haven e, por fim, em Ossining, no Estado de Nova York.

Ao longo dos anos do seu exílio (a partir de 1934), Zweig foi “desenraizado", se "expatriou", como ele mesmo disse. Como é possível ler nas cartas que escrevia na época, ele estava muito desnorteado e sem saber como e onde deveria e poderia continuar sua vida. Cogitou diversos países e cidades como domicílios adequados ao exílio para ele e sua segunda esposa Lotte. Em alguns momentos, ainda nutria (de modo irracional) a esperança de poder voltar à Inglaterra, onde havia comprado uma casa em 1939. No meu entender, o Brasil de modo geral, e Petrópolis, em particular, são dois entre diversos lugares provisórios nos caminhos emaranhados no exílio, lugares do improviso e da reflexão sobre como e onde continuar a vida depois, quando de novo seria possível estabelecer-se em algum lugar de modo permanente e estável.

Quero dizer mais uma vez que, para mim, o Brasil foi uma entre as várias opções de Zweig; a sua casa minúscula em Petrópolis também não teria sido adequada para uma estadia mais longa, a casa era apertada demais. No início, Stefan Zweig e Lotte escreviam em cartas que a paisagem lembrava-lhes sua pátria (a montanha de Semmering, a região do Salzkammergut, a cidade de Bad Ischl), mas não era sua pátria. Eles se sentiam solitários e isolados, e sofriam cada vez mais com essa solidão (embora eles mesmos a houvessem escolhido). Quase não conheciam ninguém e não tinham amigos próximos como antes, com os quais costumavam compartilhar longos períodos das suas vidas. Esse é um dos motivos pelos quais a correspondência com Friderike primeira esposa de Zweig e com a qual tivera intensos desentendimentos por ocasião da venda da sua casa em Salzburgo e do divórcio - tornou-se algo tão significativo. Mas o maior obstáculo no Brasil foi a língua: na Inglaterra e na França, Zweig sabia comunicar-se com intelectuais e artistas; no Brasil, isso se tornou algo muito difícil. Outro aspecto importante e doloroso para Zweig: por não dominar a língua, não era capaz de trabalhar nas bibliotecas. Sabemos que o trabalho concentrado em bibliotecas era fulcral para ele.

Mas mesmo os Estados Unidos foram apenas uma parada provisória. Sabemos que Zweig recebeu diversos convites de lá, mas recusou todos. Ele também enfrentara grandes dificuldades ao procurar ajudar Giuseppe Borgese e Livinia Mazzucchetti a 
serem contratados por universidades estadunidenses e entendeu que, mesmo para cientistas de excelência, a situação não era fácil. Além disso, disse em diversas ocasiões que a "esfera anglo-americana" não the convinha (para mim, esse é um comentário bastante estranho, já que ele havia residido durante mais de seis anos na Grã-Bretanha).

Na minha leitura, a obra sobre o Brasil é um tipo de livro paralelo ou, em certo sentido, até mesmo um estudo preparatório para $O$ mundo de ontem. Muitas das utopias, das ideias e dos desejos que associava ao mundo austríaco, Zweig tentou formulá-los, de modo mais sutil, em relação ao Brasil: trata-se de dois impérios formados por muitos povos, e ele via muitos paralelos entre a Áustria e o Brasil. A utopia do Brasil é, em certo sentido, uma versão da sua utopia da Europa. Enfim, o livro é apenas o resultado de um ensejo (entre muitos) para a escrita, e não um programa de vida. Ou seja, como sempre, após concluir a obra, Zweig passou a dedicar-se a outros projetos e encerrou o assunto "Brasil". Sobre a recepção do livro, muito já foi dito, sobretudo por Alberto Dines.

$\mathrm{Eu}$, pessoalmente, prefiro a ideia de que todos os livros que foram escritos durante o exílio (entre 1934 e 1941, desde Erasmo até Castélio, Magalhães, Coração inquieto, Brasil, O mundo de ontem, Clarissa, Montaigne e Xadrez) estudam e pertencem a um grande projeto intelectual. Com relação ao olhar para o mundo europeu pré-1933, Zweig procura esboçar as ideias e os valores que lhe foram importantes durante toda a sua vida e que marcaram não só a si próprio, mas também seus livros: o cosmopolitismo cultural, o humanismo, a tolerância, a luta contra a ditadura, o triunfo dos vencidos, a reconciliação dos inimigos (após a I Guerra Mundial), o pacifismo, etc. (Seria um projeto grande a altamente complexo para os estudos literários, que deveria levar em consideração também os modelos literários e aspectos comparatistas e de intertextualidade.)

Muitos outros autores (desde Alfred Döblin até os irmãos Klaus e Heinrich Mann, etc.) também escreveram retrospectivas sobre a Europa. Ou seja, Zweig pode ser estudado no contexto de uma variedade de vozes do exílio. Talvez dessa maneira muitos dos preconceitos em relação a $O$ mundo de ontem poderiam seriam desfeitos.

É claro que o suicídio de Stefan e Lotte Zweig - como todos os suicídios teve muitas motivações. Considero bastante problemático o fato de, no caso de um suicídio, a vida de uma pessoa geralmente ser avaliada a partir do seu fim. Acho isso 
muito questionável. Acredito que as mudanças políticas do governo de Getúlio Vargas e as condições de vida no Brasil ou até mesmo as decepções com a situação brasileira tenham desempenhado apenas um papel menor. Se a minha compreensão estiver correta, Zweig via em Vargas um ditador muito humano. Imagino que ele tenha se enganado nesse aspecto. Mas esse assunto tem sido muito discutido, especialmente no Brasil, e não preciso repetir isso aqui.

Além da depressão, da qual Zweig já sofria durante os anos da Inglaterra, o que o deixou tão desesperado foi sobretudo o amplo sucesso de Hitler. Os avanços dos países do Eixo, o ingresso dos Estados Unidos na Guerra e a iminente entrada do Brasil, tudo isso, somado ao medo de não conseguir escapar da Segunda Guerra Mundial, que estava se espalhando cada vez mais, deixou-o completamente desolado (como fica muito claro nas suas cartas e na introdução de $O$ mundo de ontem). Ele já não acreditava na possibilidade de enfrentar tudo isso, sobretudo por causa da sua disposição psíquica. Devia haver muitos outros motivos, tais como a ideologização de Zweig em relação à juventude, unida a seu eterno medo de envelhecer e a asma da sua esposa, por exemplo. Mas as razões centrais foram certamente a destruição da Europa e a perda irreversível do seu mundo, ao qual estava agarrado e que lhe proporcionava um sentido para a vida, mas ao qual já não podia mais voltar e ao qual não mais se adaptaria, mesmo considerando a possibilidade de uma nova orientação dos seus princípios. E esse mundo também não existia no "país do futuro". Para mim, foram esses os aspectos centrais que tanto pesaram nas suas últimas semanas e que deram tanto poder ao seu desespero. Zweig se via como um "homem de ontem", e já que esse mundo não existia mais, sua própria vida estava posta em questão.

BOHUNOVSKY: Minhas próximas perguntas referem-se à recepção de Zweig: como seus livros são lidos hoje? Quais deles são lidos? O que o torna interessante para o público de hoje? No volumoso e lindo catálogo da exposição que você editou (na verdade, uma coletânea de textos) com o título Stefan Zweig: Abschied von Europa [Stefan Zweig: despedida da Europa], há um artigo de Erika TUNNER que aborda a recepção de Zweig na França (id.:240-251), um país em que Zweig continua sendo um dos escritores de língua alemã mais lidos. Tunner procura respostas à pergunta "Como podemos explicar que os leitores atuais ainda se encantam com Zweig?”. Tunner oferece algumas respostas: Zweig é um mestre da novela psicológica; ele "domina a arte de 
analisar pessoas em momentos de crise e de mostrá-las em momentos decisivos das suas vidas"; suas narrativas seriam de um "suspense de tirar o fôlego"; e suas obras contribuiriam para confirmar nos leitores franceses suas "imagens (ideias)" sobre Viena. Você concorda com essa avaliação? Ela é válida para a recepção de Zweig em toda a Europa?

RENOLDNER: Zweig foi traduzido para todas as grandes (e também para pequenas) línguas; ou seja, teríamos que diferenciar sua recepção por país e língua. E as diferenças são grandes. Em alguns países onde Zweig viu sua obra publicada em grandes tiragens e onde teve numerosos leitores, praticamente não há interesse por ele hoje. Isso vale, por exemplo, para os Estados Unidos. Lá, Zweig foi extremamente popular no final dos anos 1930, e sua obra continuou a ser publicada e pesquisada nos anos de 1970 e 1980, mas hoje seu nome está quase esquecido. Existem algumas traduções feitas por pequenas editoras; além disso, o recente filme $O$ Grande Hotel Budapeste (2014), de Wes ANDERSON, e o ensaio biográfico The impossible exile (2014), de George PROCHNIK, trouxeram alguma atenção midiática para Zweig, durante algumas semanas. Porém, isso não muda o fato de ele, atualmente, ser um escritor desconhecido na América do Norte. O mesmo vale para a Rússia, onde Zweig foi muito presente no passado, por causa da edição de suas obras completas em 1927, por iniciativa de Maxim Gorki; pelo fato de, em 1928, ter visitado a União Soviética; e por ter escrito diversos estudos e ensaios sobre escritores russos.

Já na China, Zweig é um autor muito popular. Há uma série de traduções concomitantes - assim como, aliás, em vários outros países, especialmente após sua obra ingressar em domínio público (em 1. ${ }^{\circ}$ de janeiro de 2013). Apenas para citar um exemplo curioso, nas livrarias francesas são vendidas cinco traduções diferentes de Xadrez, e, como soube recentemente, na Turquia existem 57 diferentes tradutores que já tentaram verter textos de Stefan Zweig.

De modo geral, podemos dizer que o interesse atual por Zweig deve-se, sobretudo, a suas novelas e seus contos, ao seu romance Coração inquieto e, obviamente, a suas memórias $O$ mundo de ontem. Não nos esqueçamos de mencionar as grandes biografias sobre Maria Antonieta, Joseph Fouché e Maria Stuart. Já o poeta Stefan Zweig caiu em total esquecimento, assim como seus dramas sumiram dos teatros e praticamente ninguém se lembra das suas coletâneas de ensaios sobre literatura - que alcançaram tiragens muito altas durante a vida do autor. Nas escolas, ainda é costume 
ler a obra Momentos decisivos da humanidade. Chama a atenção que as novelas de Zweig sejam frequentemente adaptadas para encenações dramáticas, enquanto os dez dramas do autor são ignorados. E mesmo o romance Coração impaciente vem sendo muito popular entre diretores de teatro.

A França é um caso peculiar: a grande edição de luxo (aproximadamente 3 mil páginas) na renomada coleção Bibliothèque de la Pléiade, da editora parisiense Gallimard, traz em novas traduções a prosa completa de Zweig (todos os contos; Coração inquieto; O mundo de ontem, Momentos decisivos da humanidade; e até mesmo os dois fragmentos de romance Clarissa e Êxtase da transformação).

O revival de Zweig na França teve seu início em 2008 e explica-se pela reedição de algumas das suas novelas, publicadas em livros de bolso de baixo custo e de alta qualidade estética. A estratégia de venda - bastante inteligente e bem-sucedida no longo prazo - veio ao encontro da simpatia dos franceses pela belle époque de Viena, pela art nouveau, pela psicanálise e pelas transformações nas artes plásticas, na arquitetura, na música e na literatura. E, claro, foram sobretudo os contos sobre confusões eróticas as obras que causaram maior interesse. Num momento posterior, traduziram-se também os ensaios sobre política e literatura, e até mesmo as cartas. Assim, Zweig vem sendo considerado como uma figura política do seu tempo, como um intelectual europeu. $\mathrm{Na}$ França, saíram também filmes, peças teatrais, biografias em estilo de romance ou acadêmicas e até uma graphic novel. Ainda estão em preparação alguns filmes e mais publicações.

Sim, acredito que os motivos mais determinantes para o sucesso de Zweig sejam justamente esses conflitos irremediavelmente eróticos, muitas vezes trágicos, e o olhar para os "abismos da alma", a descrição fascinante das tensões internas e dos medos ou, se preferir, a frequentemente evocada "maestria psicológica" do autor. Talvez os seus textos ficcionais de maior destaque e que continuarão no cânone da literatura da sua época sejam justamente Medo, Carta de uma desconhecida, Um segredo ardente, Amok, A confusão dos sentimentos, Noite fantástica, 24 horas na vida de uma mulher e Xadrez.

$\mathrm{Na}$ França, Zweig é o autor de língua estrangeira mais lido. Na Itália e na Inglaterra, sua popularidade não é a mesma - apesar de, nos últimos anos, algumas boas editoras de menor porte terem publicado um grande número de novas edições de obras 
suas (e com novas traduções!). É interessante observar mais uma discrepância: na Alemanha e na Áustria (e provavelmente em muitos outros países), no campo dos estudos germanísticos, Zweig é visto como um "autor trivial" - e é verdade que ele não trouxe inovações estéticas nem foi um revolucionário da vanguarda. $\mathrm{O}$ fato de Hugo von Hofmannsthal e Robert Musil terem desprezado Zweig (e o fato de esses dois autores estarem em voga atualmente) ainda contribui para Zweig continuar sendo classificado como um "escritor de sexta categoria" (como disse Hofmannsthal). Outro motivo para tal desmerecimento seria ainda a ideologização do romance como gênero literário mais prestigiado - algo que não ocorre com a mesma força em todos os países. Seria possível citar outros motivos ainda.

BOHUNOVSKY: Falando em confusões eróticas: atualmente, um livro sobre a vida sexual de Zweig domina a recepção nos países de língua alemã. Trata-se de Stefan Zweigs Brennendes Geheimnis [O segredo mais ardente de Stefan Zweig - uma "biografia intima”], da autoria do jornalista vienense Ulrich WEINZIERL (2015). O livro praticamente não traz novidades, mas elas são organizadas "com diligência meticulosa" e apresentadas "de modo muito acertado" (cito sua resenha). Em que medida essa publicação é de interesse, ou relevante, não apenas em termos biográficos, mas também para a história cultural ou como base para a interpretação da literatura de Zweig?

RENOLDNER: É pouco provável que a recepção de Zweig nos países de língua alemã seja alterada por causa do livro de Weinzierl. Zweig voltou a ser assunto de discussões, o que é certamente bom, mas duvido que isso atraia novos leitores para a sua obra. O problema desse livro é seu foco exclusivo na vida sexual de Zweig. Não conheço nenhum outro escritor da literatura mundial que tenha gozado do privilégio de ter uma publicação sobre si que trate apenas desse assunto. Por que isso aconteceu justamente com Zweig, temos que perguntar a Weinzierl. Muitos não entendem essa escolha. Weinzierl já havia publicado, em 1992, uma coletânea de comentários maldosos e amargos sobre Zweig. Temos que nos perguntar por que alguém escreve dois livros sobre um autor que não aprecia. Podemos suspeitar que haja a intenção de lesar a reputação do autor em questão. Depois desse livro, Zweig já não é apenas um “escritor trivial”, apreciado pelas massas, mas também um homem pervertido e nojento, um exibicionista que assustava as meninas com intenções sádicas e, como aponta 
Weinzierl, cujo comportamento seria hoje considerado um delito contra os costumes.

Quem já leu as diversas biografias e pesquisas biográficas sobre Zweig ou suas cartas e seus diários sabe há muito tempo das suas relações e de seus casos amorosos com diferentes mulheres, assim como da sua tendência homoerótica. Realmente, isso não é nenhuma novidade. E em várias resenhas publicadas em grandes jornais alemães tem-se destacado certa decepção com o fato de boa parte das informações apresentadas já ser conhecida. A maneira como Weinzierl (no primeiro capítulo do livro) apresenta a relação entre Friderike e Stefan Zweig é muito similar ao modo como venho abordando o mesmo assunto em palestras ou em visitas guiadas nas nossas exposições. A única diferença é que no meu caso há menos notas de rodapé.

No segundo capítulo, Weinzierl apresenta os resultados de pesquisas biográficas sobre amigos homossexuais (e menos conhecidos) de Stefan Zweig, como Erwin Rieger, Erich Ebermayer, Hans Müller-Einigen e alguns outros. Isso é certamente um grande mérito. Mas maior atenção merece, sem dúvida, o terceiro capítulo, onde são reproduzidas algumas passagens do diário de Zweig com as quais Weinzierl quer comprovar que o jovem escritor tenha agido como exibicionista em parques vienenses. Nas biografias, esses episódios são geralmente citados como meros boatos, espalhados por Benno Geiger, amigo de Zweig. Weinzierl está plenamente convencido de que as pesquisas biográficas feitas até agora sobre esse tópico não têm valor e que ele apresenta, pela primeira vez, provas decisivas e irrefutáveis. É verdade que Zweig tinha conflitos com sua natureza exibicionista (e com sua identidade sexual de modo geral), mesmo se levarmos em conta que várias citações do seu diário poderiam ser lidas num sentido muito diferente da interpretação que Weinzierl lhes atribuiu. Há pouquíssimos indícios, e esse é o ponto problemático para mim. A recepção crítica do livro foi controversa e tem apontado esse fato repetidamente. Além do mais, as tentativas de Weinzierl no sentido de deduzir relações diretas e causais a partir de "informações" biográficas extraídas da poesia e da prosa de Zweig (por exemplo, em Noite fantástica) e de querer comprovar suas teses biográficas a partir do eu-lírico e do comportamento de personagens literárias me parecem ser bastante míopes (e insustentáveis do ponto de vista acadêmico). Isso é estranho no caso de um autor que já angariou reconhecimento considerável, inclusive na germanística, por seus estudos sobre Arthur Schnitzler e Hugo von Hofmannsthal.

“Sex sells”, escreveu o jornal suíço Neue Zürcher Zeitung. E as declarações da 
editora, que ficou feliz com a enorme presença midiática do livro, comprovam esse objetivo. Mas tenho certeza de que, assim que acabar esse pequeno impacto mediático, voltaremos aos desideratos da pesquisa científica e aos temas que realmente interessam. Esse é justamente o problema do livro de Weinzierl, que ignora por completo a obra literária de Zweig (comenta apenas o livro A confusão dos sentimentos). Muitos estudiosos da literatura notaram tal aspecto. Sei disso por causa dos muitos e-mails que recebi de colegas do mundo todo. A que conclusão podemos chegar? Uma discussão sobre as representações do homem e da mulher nos textos ficcionais de Zweig - em relação à temática abordada - teria acrescentado várias informações interessantes. Do modo como foi feito, trata-se apenas de uma pequena biografia íntima. Sentimos falta do horizonte histórico-cultural. Mesmo a notável passagem "Eros Matutinos", de $O$ mundo de ontem, foi praticamente ignorada no livro de Weinzierl, embora nela possamos encontrar muitas pistas sobre o ponto de vista de Zweig.

BoHUnOvsKY: Voltemos aos livros de Stefan Zweig e sua recepção: O mundo de ontem $e$ Brasil - um país do futuro foram, desde o início, alvo de severas críticas. Já no ano da sua primeira publicação, o livro sobre o Brasil foi resenhado de modo desastroso por jornalistas brasileiros e críticos (do regime de Vargas). Em 1992, Izabela KESTLER se referiu à obra como um "livro de contos de fada". Numa exposição sobre o famoso grupo de filósofos do Círculo de Viena (na Universidade de Viena, em 2015), foi exibido um exemplar da primeira edição de $O$ mundo de ontem, pertencente ao espólio do austríaco Otto Neurath (filósofo da ciência, sociólogo e economista político). As primeiras páginas, expostas na mostra, estão repletas de comentários escritos à mão por Neurath. (Por exemplo: "a rather grotesque description of the past as an ideal of peace and security. The Metternich-tradition: terrible!”. Ou um comentário acerca da frase de Zweig "Each family hat its fixed budget": "what about the unemployed, the poor?”). Parece-me interessante pensar por que esses livros, que aparentemente não resistem a nenhuma análise crítica, ainda são lidos (e muito) e ainda são publicados em novas traduções. As apresentações utópico-nostálgico-harmônicas dos dois países nos "livros paralelos", como você os chamou acima, ainda servem para gerar empatia com o leitor? Estaria acontecendo, como Zweig abordou em Balzac, de "a literatura vencer a história", a ficção vencer os fatos?

RENOLDNER: É muito interessante você mencionar os comentários de Otto 
Neurath, nessa excelente exposição sobre o Círculo de Viena, na Universidade de Viena. Trata-se de um documento da história da recepção, encontrado recentemente por Friedrich Stadler. Sim, esse tipo crítica acerca de $O$ mundo de ontem tem uma longa história. A testemunha principal (e frequentemente citada) dessa posição é Hannah Arendt - uma emigrante europeia de origem judaica, assim como Zweig! - que, já depois da guerra, transformou uma resenha sobre esse livro em um polêmico ensaio contra Zweig. O que ela constata nos comentários de Zweig sobre seu exílio é uma incompreensível hipersensibilidade burguesa e luxuosa. Ela se ressente de Zweig não se sentir como um judeu perseguido, e reclama de ele se ver como um representante da cultura europeia. Também objeta o fato de Zweig não abordar a política real da monarquia austríaca, os conflitos nacionais e os problemas sociais de Viena e da Áustria. Essa linha negativa da recepção existe até hoje.

Acredito que $O$ mundo de ontem resiste, sim, a uma análise crítica. Com um gesto de descontentamento, costuma-se confrontar o livro com grandes expectativas. Mas alguém já se perguntou o que o próprio Zweig realmente pretendia? Talvez sua concepção tenha sido bem diferente do que se supõe hoje. Temos de ser mais cautelosos. Às vezes, parece que se acusa um banco verde de não ser azul. Porém, observo repetidamente que esse livro é bastante citado, mesmo por germanistas internacionais conhecidos por desprezarem Zweig. Tem até um chavão, que já ouvi de muitos estudiosos e cujo teor é mais ou menos assim: "Não aprecio muito Stefan Zweig como escritor, mas sua autobiografia é um livro fascinante e gosto de usá-lo nas minhas aulas/pesquisas". Mais ou menos assim.

Pois $O$ mundo de ontem possui - apesar das objeções, algumas das quais certamente justificadas - muitas qualidades, tais como o capítulo sobre a moral sexual e a dupla moral na Áustria de 1900. Em minha opinião, trata-se de um estudo histórico-cultural notável sobre o tema - em que os homens não se saem muito bem. A avaliação da situação política na Áustria dos anos de 1930, o prefácio comovente e, naturalmente, os últimos capítulos (sobre o sucesso de Hitler, a perseguição aos judeus, a problemática do exílio, etc.), tudo isso demonstra uma enorme perspicácia e compreensão política. Porém, são passagens menos conhecidas, se comparadas às que se referem à época pré1914.

Para mim, trata-se menos de um texto com o qual os leitores possam se identificar. Nem considero de prima importância o aspecto "utópico-nostálgico- 
harmônico" (mais um dos clichês sobre $O$ mundo de ontem!). É correto que dois terços do livro se dedicam ao tempo anterior a 1914. Mas não se encontra nesse livro nenhuma saudade antidemocrática da monarquia, do velho imperador. A partir das críticas justificadas de Hannah Arendt ou de Otto Neurath, formou-se certo senso comum, mas este não passa de um clichê. Nos seus últimos anos de vida, Joseph Roth realmente se transformou num monarquista, pois esperava poder opor-se à loucura nazista com uma ação e um programa que defendesse uma velha Áustria idealizada. Zweig nunca defendeu essa posição, e considerou absurdas as tentativas de formar uma aliança política liderada por Otto von Habsburg. Ou seja: não há nenhuma nostalgia pelo intacto mundo antigo dos Habsburgos em $O$ mundo de ontem. Trata-se de um clichê, uma simplificação excessiva, e seria necessário analisar cada linha de cada página do livro.

Também não devemos esquecer o momento em que o livro (na sua última versão) foi escrito. Isso ocorreu em julho de 1941, nos Estados Unidos. Zweig, então com 59 anos, sabia o que estava acontecendo com os judeus nos campos de concentração, e ele sabia que a guerra ofensiva estava sendo executada com toda força. A Áustria, a pátria de Zweig, havia sumido do mapa, e a Europa, sua pátria cultural e ideológica, havia sido destruída por governos antidemocráticos. Estava em andamento uma guerra ainda mais cruel que a de 1914-1918. Mesmo nessa situação trágica e desesperadora, e sofrendo de uma grave depressão, Zweig, como sabemos hoje, continuava escrevendo diariamente esse livro. E ainda assim o acusamos de não mencionar a agressividade com a qual a Áustria agia contra a Sérvia, nos anos que precederam 1914? E de não mencionar a situação lamentável dos trabalhadores da Boêmia contratados pelas fábricas de tijolo de Viena? O pano de fundo dessa obra bem como a sua intenção original, não têm nada a ver com isso. Parece-me muito compreensível que alguém confrontado com a demolição da velha Europa, com a extinção da cultura judaica, queira lembrar-se dos anos felizes da sua vida.

BOHUNOvSKY: Ou seja, na leitura dessa obra, não devemos ignorar o contexto no qual foi escrito. Isso corresponde à sua afirmação (feita acima) de que o interesse pela vida e pela obra de Zweig está principalmente na sua relação com a história política da Áustria e da Europa. E é justamente do contexto histórico que trata o livro A rede de amigos de Stefan Zweig: sua última agenda (1940-1942), ou A Network of Friends, Stefan Zweig, his last address book, 1940-1942, publicado em 2014, nas línguas 
portuguesa e inglesa. O organizador do livro é Alberto Dines, biógrafo brasileiro de Zweig. O que torna uma agenda tão interessante para colocá-la à disposição do público? O livro foi publicado também em alemão ou existem planos para uma versão em alemão?

RENOLDNER: Esse livro - que, salvo duas pequenas anotações feitas por Zweig, foi escrito integralmente pela segunda esposa dele, a Lotte - será publicado em breve também na Alemanha, talvez já em 2016. O que torna essa agenda brasileira algo especial é que, por um lado, contém quase exclusivamente nomes de amigos que também emigraram e, por outro lado, contatos de muitos novos conhecidos e de instituições nos Estados Unidos e na América Latina. A ausência de vários nomes que se esperaria que estivessem presentes chama a atenção. Ou seja, constitui um documento especial da nova orientação de Zweig no exílio, tanto nos Estados Unidos quando no Brasil.

É bem provável que Zweig guardasse também sua agenda anterior, iniciada na Inglaterra, e que contém todos os nomes e endereços europeus. Mas a primeira impressão causada pela agenda que ficou no Brasil é a de que se trata de um testemunho de um novo começo radical - parece que a despedida da Europa foi consumada.

BOHUNOVSKY: Na sua despedida da Europa, Zweig teve de separar-se da sua coleção de manuscritos, composta exclusivamente por escritos originais (não contém correspondências, etc.). O escritor Richard Beer-Hoffmann, que comentou a entrega da coleção à Biblioteca Nacional da Áustria, em 1937, num jornal de Viena, disse que Zweig procurava entender "o momento criativo na escrita” MÜHLEGGER-HENHAPEL in: RENOLDNER 2014: 223). Qual foi a relevância dessa coleção para a vida e a obra de Stefan Zweig?

RENOLDNER: A história da coleção de manuscritos de Stefan Zweig está muito bem documentada no livro Conheço a mágica da escrita, de Oliver MATUSCHEK, publicado em 2005, em Viena. O livro reúne todos os textos de Zweig que ajudam explicar seu entusiasmo pelos originais e seus motivos como colecionador. Não há muito a se acrescentar. Até 1922/23, Stefan Zweig foi um colecionador apaixonado. Deve ter investido grandes quantias na aquisição de originais de Goethe, Heine, Büchner, etc., assim como partituras originais de Mozart, Beethoven, Schubert, Haydn, 
etc. Com esses textos, estudou o processo artístico, a materialização do pensamento, a luta com uma ideia. Com ajuda desses documentos, conseguiu aproximar-se das pessoas sobre as quais pretendia escrever.

BOHUNOVSKY: Antes de encerrar, gostaria de fazer uma pergunta mais concreta sobre Stefan Zweig e o Brasil. Na casa onde morava, em Petrópolis, encontra-se hoje a sede da associação Casa Stefan Zweig, um lugar de memória para Zweig e outros artistas exilados. Como acontece a cooperação entre o Brasil e a Áustria, e entre a Casa Stefan Zweig no Rio e o Stefan Zweig Centre em Salzburgo? Há publicações ou projetos em comum? Quais são as chances de trazer a exposição para o Brasil? Há algum tempo, existem interesses e esforços sendo feitos nesse sentido. Já se chegou a algum resultado mais concreto?

RENOLDNER: A cooperação com a Casa Stefan Zweig é algo muito positivo. Já me encontrei com Alberto Dines algumas vezes, na Alemanha e, recentemente, em Salzburgo, e falo regularmente por telefone com Kristina Michahelles. Já nos reunimos diversas vezes, e mantemo-nos informados sobre as atividades uns dos outros. Até agora, publicamos em conjunto dois livros. O primeiro foi o catálogo de uma exposição sobre Giuseppe Germani, libertado da prisão após Zweig escrever uma carta a Mussolini. Um artigo importante para esse catálogo veio de Arturo Larcati, do Stefan Zweig Centre, de Salzburgo. O segundo foi o planejamento para a edição fac-símile da última agenda de Zweig, a partir do espólio brasileiro. Como já mencionei, o livro será publicado em alemão em 2016.

Trabalhamos juntos em diversas ocasiões: na aquisição ou reprodução de textos, fotos, filmes, documentos, etc. A ajuda mútua tem sido maravilhosa. Ultimamente, estamos conversando com a Universidade de São Paulo a respeito de uma conferência sobre Stefan Zweig, na primavera de 2017, por ocasião do $75 .^{\circ}$ aniversário da sua morte. É óbvio que a Casa Stefan Zweig será um dos organizadores. É óbvio, também, que Alberto Dines será o principal palestrante. Estamos conversando, ainda, sobre outros projetos para livros e exposições que queremos organizar em conjunto. Realmente, essa pareceria tem sido excelente.

Nossa exposição sobre Stefan Zweig e seus anos no exílio, e em cujo centro estão trabalhos profundamente ligados a essa última fase da vida de Zweig, poderia, ou 
melhor, deveria ser exibida também no Brasil. Meus contatos e parceiros no Brasil têm mostrado grande interesse. No dia 23 de novembro de 2015, vamos inaugurar a exposição na Biblioteca Nacional da Alemanha em Frankfurt. Temos bastante orgulho de poder mostrá-la num lugar tão representativo. A mostra vai ficar lá até março de 2016. Depois disso, já poderia viajar ao Brasil. Há alguns meses, pareceu-me que a Embaixada Austríaca em Brasília tivesse interesse em levar a exposição ao Brasil e de que já houvesse alguns patrocinadores privados dispostos a responsabilizar-se pelo transporte transatlântico das peças e pela montagem e desmontagem da mostra. Estamos com a documentação toda pronta, apenas esperando que Brasília diga "sim, vamos montar a exposição". Torçamos para que dê tudo certo - se não em 2016, talvez em $2017 ?$

BOHUNOVSKY: Esperamos que seja possível apresentar a exposição em solo brasileiro. A conferência sobre Stefan Zweig em 2017 parece ser o contexto ideal, além da relação da exposição com o Brasil. Agradecemos muito pela conversa interessante e instigante.

Trad. Ruth Bohunovsky

\section{Referências bibliográficas}

BACK, Silvio. Stefan Zweig - Der inszenierte Tod. [A morte em cena]. Dokumentarfilm. Regie; Sylvio Back, Brasilien, 1995.

BELOCH, Israel. Org. A rede de amigos de Stefan Zweig: sua última agenda (1940-1942); A network of friends. Stefan Zweig : his last address book 1940 - 1942 / Alberto DiNES, introdução ; Israel BELOCH, organização. Alberto DINES, Kristina MICHAHELLES, Israel BELOCH, pesquisa e textos. Petrópolis : Casa Stefan Zweig, 2014.

CASA STEFAn ZWEIG. http://www.casastefanzweig.org/ (01/11/2015).

GöRNER, Rüdiger/ RENOLDNER, Klemens. Zweigs England. Schriftenreihe des Stefan Zweig Centre Salzburg. Würzburg: Könighausen und Neumann, 2015.

KESTLER, Izabela Maria Furtado. Die Exilliteratur und das Exil deutschsprachiger Schriftsteller und Publizisten in Brasilien. Frankfurt am Main: Lang, 1992.

MATUSCHEK, Oliver. Ich kenne den Zauber der Schrift. Wien: Inlibris 2005.

MÜHLEGGER-HENHAPEL. Christiane. «Etwas wunderbar Substansloses ...» Die Autographensammlung Stefan Zweigs im Wiener Theatermuseum. In: RENOLDNER, Klemens (Hg.). Stefan Zweig - Abschied von Europa. Wien, Theatermuseum und Christian Brandstätter Verlag, 2014, 214-238.

RENOLDNER, Klemens. Lilys Ungeduld. Wien: Folio, 2011.

RENOLDNER, Klemens (Hg.). Stefan Zweig - Abschied von Europa. Wien, Theatermuseum und 
Christian Brandstätter Verlag, 2014.

RENOLDNER, Klemens. Angstlust. In: Die Presse, Wien. 19. September 2015.

STEFAN ZWEIG CENTRE SALZBURG. http://www.stefan-zweig-centre-salzburg.at/ (01/11/2015).

TUNNER, Erika, Zur jüngsten Zweig-Renaissance. Am Beispiel: Frankreich. In: RENOLDNER, Klemens (Hg.). Stefan Zweig - Abschied von Europa. Wien, Theatermuseum und Christian Brandstätter Verlag, 2014, S. 241-252.

WEINZIERL, Ulrich. Stefans Zweigs Brennendes Geheimnis. Berlin: Zsolnay 2015.

ZwEIG, Stefan. Schachnovelle. Hg. v. Klemens Renoldner. Stuttgart: Reclam, 2013.

ZWEIG, Stefan. O mundo insone e outros ensaios. Übersetzt von Kristina Michahelles. Rio de Janeiro: Zahar, 2013.

ZWEIG, Stefan. Maria Antonieta. Übersetzt von Irene Aron. Rio de Janeiro: Zahar, 2013.

ZWEIG, Stefan. Autobiografia: o mundo de ontem. Übersetzt von Kristina Michahelles. Rio de Janeiro: Zahar, 2014.

ZwEIG, Stefan. Três novelas femininas - Medo, Carta de uma desconhecida, 24 horas na vida de uma mulher. Übersetzt von Adriana Lisboa, Raquel Abi-Sâmara. Rio de Janeiro: Zahar, 2014.

ZWEIG, Stefan. Joseph Fouché - retrato de um homem político. Übersetzt von Kristina Michahelles. Rio de Janeiro: Zahar, 2015.

Zweig, Stefan. Novelas insólitas - Segredo ardente, Confusão de sentimentos, A coleção invisivel, Júpiter, Foi ele?, Xadrez - uma novela. Übersetzt von Maria Aparecida Barbosa, Kristina Michahelles und Murilo Jardelino. Rio de Janeiro: Zahar, 2015. 